\title{
Ovarian Torsion: A Gynecological Emergency
}

\author{
${ }^{1}$ Nupur Garg, ${ }^{2}$ Deepika Krishna, ${ }^{3}$ Suvarna Rathor, ${ }^{4}$ Kamini A Rao
}

\begin{abstract}
Ovarian torsion is an uncommon gynecological emergency that requires prompt recognition and treatment. Timely investigation and management can make the difference between ovarian loss and salvage, an outcome of great importance in the population of reproductive age females. Our case series is about clinical presentation and management approach of adnexal torsion in a tertiary care fertility center. Adnexal torsion was found mainly in the reproductive age during poststimulation postovulatory period in all cases. Ultrasound was the most commonly used imaging modality. Ovarian stimulation was the risk factor seen in all the patients. Diagnosis of adnexal torsion was mostly clinical. Laparoscopy was the preferred method of surgical intervention. Ovarian conservation was possible in all cases except one.
\end{abstract}

Keywords: Color Doppler sonography, Laparoscopy, Ovarian torsion.

How to cite this article: Garg N, Krishna D, Rathor S, Rao K. Ovarian Torsion: A Gynecological Emergency. Int J Infertil Fetal Med 2015;6(3):136-140.

Source of support: Nil

Conflict of interest: None

Date of received: $08-10-15$

Date of acceptance: $11-11-15$

Date of publication: December 2015

\section{INTRODUCTION}

The incidence of ovarian torsion after in vitro fertilization (IVF) treatment has been reported to range from 0.08 to $0.2 \%{ }^{1,3}$ Ovarian hyperstimulation syndrome (OHSS), particularly if associated with pregnancy, may be by itself a risk factor for ovarian torsion. ${ }^{2}$ An early diagnosis of adnexal torsion is crucial because it may provide the opportunity to preserve the ovary; however, delay and difficulty in the diagnosis may be encountered because the presenting features of OHSS itself, namely abdominal

\footnotetext{
${ }^{1,3}$ Fellow Reproductive Medicine, ${ }^{2}$ Consultant Specialist ${ }^{4}$ Director

${ }^{1}$ Department of Obstetrics and Gynecology, Milann-The Fertility Center, Bengaluru, Karnataka, India

${ }^{2-4}$ Department of Reproductive Medicine, Milann-The Fertility Center, Bengaluru, Karnataka, India
}

Corresponding Author: Nupur Garg, Fellow Reproductive Medicine, Department of Obstetrics and Gynecology, MilannThe Fertility Center, Bengaluru, Karnataka, India, Phone: 9008142947, e-mail: nupurgargsa@yahoo.com distension and tenderness, can mimic signs of ovarian accidents. The use of color Doppler sonography has proved useful for an earlier diagnosis but it may not be always diagnostic, so clinical acumen is of great importance in deciding the management.

\section{METHODS}

A retrospective analysis of hospital charts, of all patients with a diagnosis of ovarian torsion at Milann-The Fertility Center from 2009 to 2015. Clinical information obtained from the patient's medical records included age, medical history, clinical signs and symptoms, management and outcome. Abdominal pain was defined as lower abdominal pain (pelvic), diffuse pain and epigastric pain. Associated symptoms like fever, nausea, vomiting were recorded. Aggravating and relieving factors were noted. The onset of pain till admission to the hospital was noted in days. Imaging and operative findings were obtained from the case records. Our case series present different clinical scenarios of 10 infertility patients with surgically proven adnexal torsion.

\section{Clinical Presentation}

The median age of the patients in our case series was 31 years (24-39 y). Lower abdominal pain was the main symptom. Apart from pain, other clinical signs and symptoms were nausea, vomiting, dysuria, urinary retention, diarrhea, constipation and bleeding per vaginum. In our patients, nonspecific diffuse tenderness was seen in all cases. All cases of torsion in our series were postovarian stimulation and polycystic ovaries were seen in three cases on their day 2 scan. Two out of 10 cases were postintrauterine insemination (IUI) stimulation, one case of timed intercourse and rest seven cases were post IVF stimulation.

Ultrasound was performed in all cases and enlarged ovaries were reported. Doppler was done in five cases, all cases showed normal blood flow (Fig. 1) except one where clinical diagnosis was complemented with positive Doppler findings. The other ultrasound findings were ovarian cyst, ovarian cyst with free fluid in pouch of Douglas.

Ovarian torsion was diagnosed only during surgery in one of the cases presenting with concurrent heterotopic pregnancy. The patient presented with lower abdominal pain and was diagnosed to be a case of heterotopic 


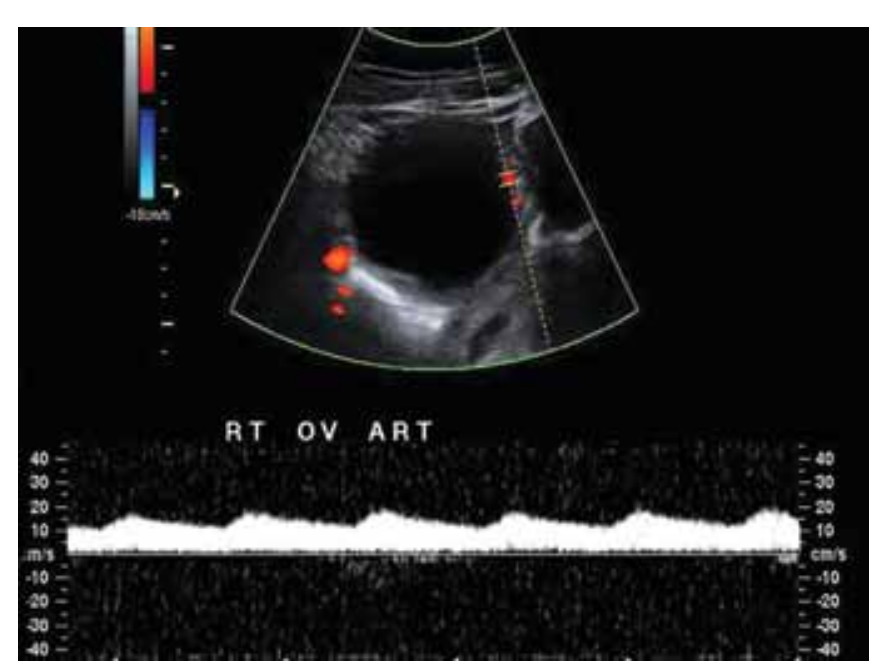

Fig. 1: Color Doppler image showing normal waveform in ovarian artery

pregnancy but only during exploration incidental diagnosis of ovarian torsion was made (Fig. 2).

Torsion occurred in four cases during immediate postovulatory period while six cases presented in early pregnancy with torsion. Salpingectomy was done in one case presenting with concurrent heterotopic pregnancy owing to unhealthy nature of the tube. Corpus luteal cysts were ruptured during surgery to prevent recurrence in two pregnant patients presenting with torsion and were put on intensive luteal support with combined estrogen and progesterone preparations till 10 weeks of pregnancy. All the pregnancies continued uneventfully postoperatively without any mishap till term.

In all cases, there was domination of right ovarian ligament torsion except in one case where left infundibulopelvic ligament was torsed. The same case also presented with recurrent torsion. Totally four episodes of torsion occurred in the same patient. First episode involved left infundibulopelvic ligaments later three episodes involved right ovarian ligament. The precipitating factor during

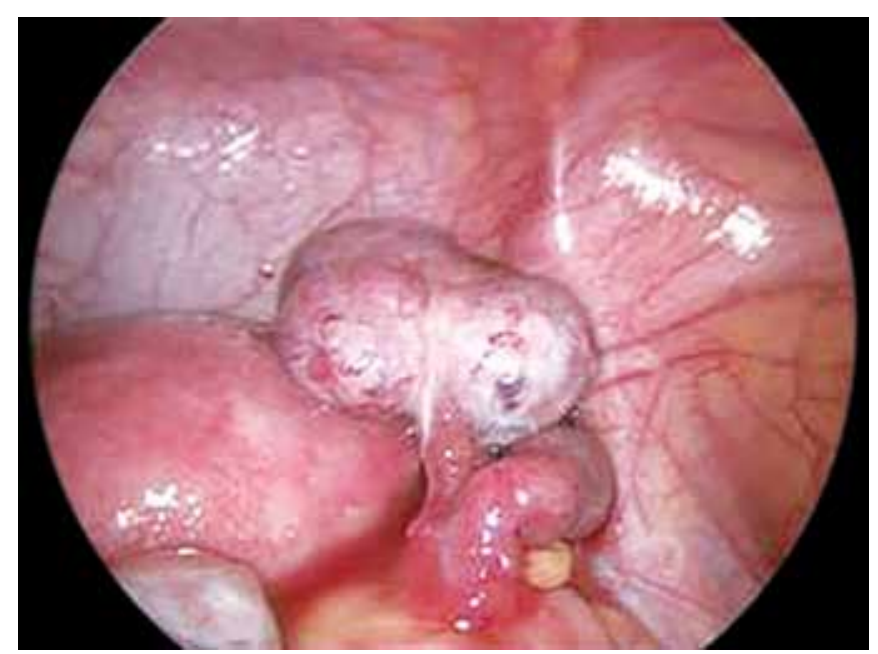

Fig. 2: Right ovarian torsion with right sided tubal ectopic pregnancy all the episodes was straining at stools. This was an interesting case of sequential bilateral ovarian torsion in our case series which has been reported to be very rare in the literature.

\section{Surgery}

All the patients underwent laparoscopic surgical procedure. The surgical findings were isolated ovarian torsion in nine cases and combined ovarian and fallopian tube torsion in one case. All the findings are summarized in Table 1. The risk factors for adnexal torsion found in our study were hyperstimulated ovaries in all the cases.

The size of the mass in adnexal torsion was 5 to $10 \mathrm{~cm}$ in nine cases and greater than $10 \mathrm{~cm}$ in one case. In all the cases, the torsed ovary was displaced high up from the pelvis. Right-sided torsion was seen in all cases except one where there was an initial left-sided torsion followed by all right-sided episodes in nine cases.

Out of the 10 cases, nine had right ovarian torsion. One case presented with recurrent torsion with ovarian torsion occurring on left side in the first episode followed by three episodes of right ovarian torsion. Case of recurrent torsion was managed by cyst puncture and chronic laxative therapy as constipation was precipitating factor all the times. Fixation of the ovarian ligament could not be done owing to fragile nature of the ovarian tissue.

Detorsion was done in nine cases, salpingo-oophorectomy in one owing to irreversible damage to ovarian tissue due to prolonged ischemia. Salpingectomy was done in one case due to concurrent heterotopic pregnancy of the same side. Cyst puncture was done in three cases to avoid retorsion

Hemoperitoneum with clots in pouch of Douglas was seen in three cases where ovarian tissue also appeared ischemic. Ovarian tissue appeared completely discolored and devitalized. Inspite of ischemic appearing ovaries, successful conservative surgery was done in two cases and return of vascularity was achieved (Fig. 3). Followup over a period of 1 month showed normal follicles in salvaged ovaries. One case detorsion was not possible due to irreparable damage to the ovarian tissue. Ovary was enlarged and gangrenous and twisted twice over the pedicle $15 \times 15 \mathrm{~cm}$, with $500 \mathrm{ml}$ of hemoperitoneum. Detorsion was not possible due to large size and friability of right ovary. Salpingo-oophorectomy with drainage of hemoperitoneum was done (Fig. 4).

\section{DISCUSSION}

Ovarian torsion is responsible for $\leq 3 \%$ of all gynecologic emergencies. ${ }^{4-8}$ Many anatomic and physiologic factors predispose a woman to experience torsion of the ovary, but the true etiology is not always identified. Pregnant 
Table 1: Summary of case series

\begin{tabular}{|c|c|c|c|c|c|c|c|c|c|}
\hline Cases & Age & Episode & $A R T$ & $\mathrm{COI}$ & $\begin{array}{l}\text { Size of } \\
\text { ovary }\end{array}$ & Doppler & Pregnant & $G A$ & $\begin{array}{l}\text { Intraoperative findings and surgical } \\
\text { management }\end{array}$ \\
\hline 1 & 24 & 1 & IUI & PCOS & $10 \times 9 \mathrm{~cm}$ & Normal & Twins & $\begin{array}{l}7 \text { weeks } \\
6 \mathrm{~d}\end{array}$ & $\begin{array}{l}\text { ROL torsed by } 2 \text { rotations. } \\
\text { Detorsion done }\end{array}$ \\
\hline 2 & 30 & 1 & $\mathrm{TI}$ & $\begin{array}{l}\text { Unex- } \\
\text { plained }\end{array}$ & $10 \times 6 \mathrm{~cm}$ & $\begin{array}{l}\text { Dec- } \\
\text { reased }\end{array}$ & Singleton & $\begin{array}{l}6 \text { weeks } \\
3 d\end{array}$ & $\begin{array}{l}\text { ROL torsed by } 2 \text { rotations. Detorsion with } \\
\text { puncture of cyst }\end{array}$ \\
\hline 3 & 31 & 1 & IVF & PCOS & $10 \times 8 \mathrm{~cm}$ & ND & $\begin{array}{l}\text { Not } \\
\text { pregnant }\end{array}$ & - & $\begin{array}{l}\text { ROL torsed by } 2 \text { rotation. Ovary bluish } \\
\text { black, signs of rupture present ovarian } \\
\text { tissue fragile bleeding from surface++ } \\
\text { Detorsion. Puncture of cysts done. }\end{array}$ \\
\hline 4 & 26 & 1 & IVF & $\begin{array}{l}\text { Endome- } \\
\text { triosis }\end{array}$ & $10 \times 10 \mathrm{~cm}$ & ND & $\begin{array}{l}\text { Heterotopic } \\
\text { pregnancy }\end{array}$ & 7 weeks & $\begin{array}{l}\text { Right tubal unruptured ectopic pregnancy } \\
\text { of } 2 \times 2 \mathrm{~cm} \text {. ROL torsed by } 2 \text { rotations. } \\
\text { Detorsion. Right sided salpingectomy }\end{array}$ \\
\hline \multirow[t]{3}{*}{5} & 31 & 4 & IVF & Male factor & $10 \times 10 \mathrm{~cm}$ & Normal & Singleton & $\begin{array}{l}5 \text { weeks } \\
2 d\end{array}$ & $\begin{array}{l}\text { 1st episode: Left infundibulo-pelvic ligment } \\
\text { torsed by } 1 \text { rotations. Subdiaphragmatic and } \\
\text { POD FLUID + Detorsion done }\end{array}$ \\
\hline & & & & & & & & & $\begin{array}{l}\text { 2nd episode (after } 9 \text { days): Torsion of right } \\
\text { ovarian ligament by } 3 \text { circle, detorsion done }\end{array}$ \\
\hline & & & & & & & & & $\begin{array}{l}\text { 3rd episode (after } 13 \text { days): torsion of right } \\
\text { ovarian ligament by } 1 / 2 \text { circle, detorsion done } \\
\text { 4th episode (after } 3 \text { days): Right ovarian } \\
\text { ligament, torsed by } 2 \text { circles, ovary was } \\
\text { detorsed and cyst was punctured to prevent } \\
\text { retorsion }\end{array}$ \\
\hline 6 & 39 & 1 & IVF & PCOS & $10 \times 8 \mathrm{~cm}$ & $\begin{array}{l}\text { Incon- } \\
\text { clusive }\end{array}$ & $\mathrm{NP}$ & - & $\begin{array}{l}\text { ROL torsed by } 2 \text { rotations ovarian tissue } \\
\text { completely discolored and devitalized. } \\
\text { Blood supply could not be restored even } \\
\text { after detorsion. Hemoperitoneum } 23 \text { litres } \\
\text { right salpingo-oophorectomy with drainage } \\
\text { of hemoperitoneum }\end{array}$ \\
\hline 7 & 27 & 1 & IVF & Donor & $7 \times 5 \mathrm{~cm}$ & Normal & - & - & $\begin{array}{l}\text { ROL torsed by } 1 / 2 \text { rotations. Detorsion } \\
\text { done }\end{array}$ \\
\hline 8 & 28 & 1 & IVF & Male factor & $12 \times 10 \mathrm{~cm}$ & ND & TCTA & 7 weeks & $\begin{array}{l}\text { ROL torsed by } 1 \text { and } 1 / 2 \text { rotations } \\
\text { Detorsion done }\end{array}$ \\
\hline 9 & 26 & 1 & IUI & Male factor & $9 \times 8 \mathrm{~cm}$ & ND & TCTA & $\begin{array}{l}4 \text { weeks } \\
5 d\end{array}$ & $\begin{array}{l}\text { ROL torsed by } 1 \text { and } 1 / 2 \text { rotations. } \\
\text { Detorsion done }\end{array}$ \\
\hline 10 & 31 & 1 & IVF & Male factor & $10 \times 9 \mathrm{~cm}$ & ND & - & - & $\begin{array}{l}\text { ROL torsed by } 2 \text { roations. Right ovary } \\
\text { placed high up. Gangrenous tissue present } \\
\text { over surface of ovary. Detorsion done }\end{array}$ \\
\hline
\end{tabular}

TI: Timed intercourse, IUI: Intrauterine insemination, IVF: In vitro fertilization, TCTA: Triamniotic trichorionic pregnancy, ND: Not done, ROL: Right ovarian ligament, PCOS: Polycystic ovarian syndrome

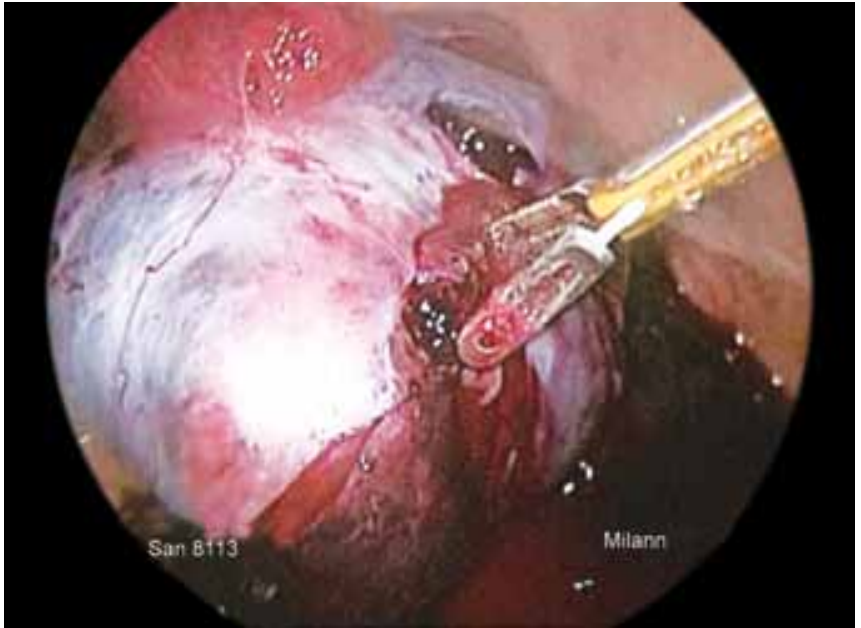

Fig. 3: Ischemic appearing ovarian tissue salvaged with conservative treatment

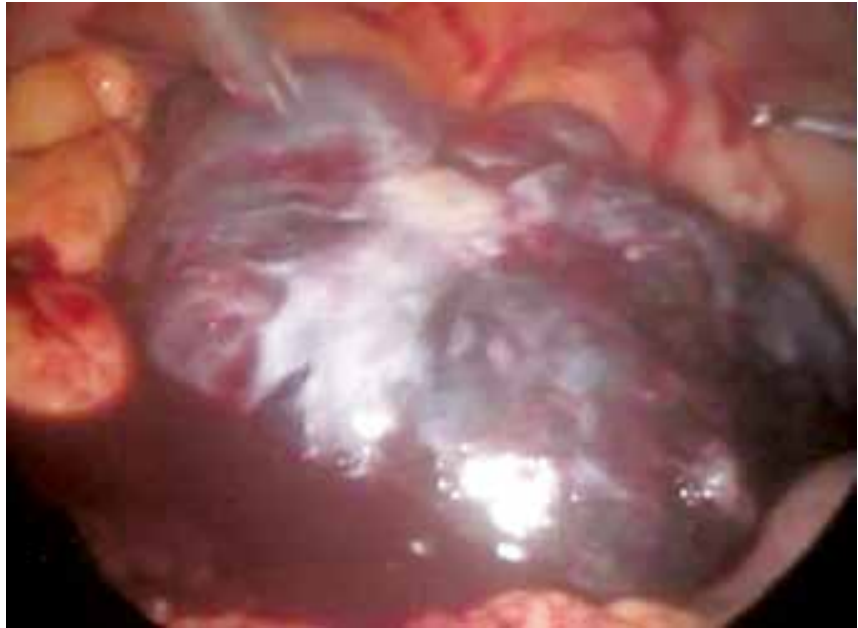

Fig. 4: Gangrenous ovarian tissue with massive hemoperitoneum 
women who conceive as a result of controlled ovarian stimulation are at greater risk for the development of ovarian torsion ${ }^{5,6}$ as seen in our case series. With an increasing number of women undergoing assisted reproductive technology with controlled ovarian stimulation, it is essential for physicians to suspect ovarian torsion when confronted with a patient presenting with acute onset abdominal pain, nausea, and/or vomiting. Torsion can be a severe complication after ovarian stimulation, and it frequently may accompany OHSS. ${ }^{9,10}$ As symptoms are mainly nonspecific, ovarian torsion often may be confused with other conditions including a ruptured corpus luteum cyst, adnexal abscess, ovarian hyperstimulation, urinary obstruction, heterotopic pregnancy, and appendicitis. ${ }^{9}$ Ovarian torsion was diagnosed only after surgery in one of our case presenting with heterotopic pregnancy. In all the remaining nine cases ovarian torsion was suspected on clinical presentation which was confirmed on surgical exploration and Doppler was conclusive of ovarian torsion in only one case.

Torsion occurs when the ovary twists around its pedicle. This may be due to increased length of the infundibulopelvic or ovarian ligaments, cysts that increase the size of the ovary and make it more mobile, or pregnancy as the uterus enlarges and rotates, changing the position of the ovary. ${ }^{10}$ The first signs and symptoms of torsion develop when decreased venous and lymphatic return increases the size of the ovary, eventually arterial supply to the ovary is restricted as well, leading to ischemia and necrosis if left untreated. ${ }^{4,8}$ It is crucial to identify torsion early to preserve the ovary. However, in cases in which the diagnosis is delayed and the ovary is found to be black or bluish in appearance on surgical examination, the ovary still may be salvageable. This implies that full arterial constriction does not often occur; rather the edema and venous stasis may cause the mottled appearance of the affected ovary. ${ }^{4,6}$

The imaging study of choice to diagnose ovarian torsion is Doppler ultrasound, as it may show absent or reduced blood flow to the ovary. ${ }^{8}$ The ovary appears unilaterally enlarged with edema and multiple cystic structures that often are accompanied by some degree of ascites. ${ }^{6,9}$ Although it is possible to use Doppler flow to diagnose torsion, it has been shown that Doppler may miss up to $60 \%$ of cases as there is often no change in vascular flow. ${ }^{5-7}$ In such cases, a strong clinical suspicion of ovarian torsion must lead to laparoscopic evaluation.

Because diagnosis of adnexal torsion is usually uncertain and surgical intervention is likely to be delayed, these infertile women risk losing their ovaries. The clinical picture of torsion of adnexa in patients with OHSS is presented in our case series. The combination of ovarian enlargement, abdominal pain, nausea, might indicate torsion of adnexa. Taskin et $\mathrm{al}^{11}$ showed that even with complete ischemia gross appearance does not correlate with outcome and that detorsion within 24 hours did not show an increase in free radical reperfusion injury. In one of our cases inspite of hemorrhagic nature of the ovarian tissue detrosion resulted in achievement of normal functionality of the ovary. In all the nine patients intraoperative unwinding of the adnexa was performed, but only in one patient inspite of timely intervention ovary could not be salvaged. This highlights the necessity of timely interventions in such cases specially in hyperstimulated patients. In stimulated patients clinical picture of torsion can also be confused with ectopic pregnancy as was the case in one of our patient with heterotopic pregnancy presented with same side torsion of right ovary. The right ovary is 50\% more likely to twist and cause torsion than the left, implying that the sigmoid colon may protect against torsion. ${ }^{9}$ This was also confirmed in our case series as all 10 cases presented with right-sided ovarian torsion. Smorgick et $\mathrm{al}^{9}$ in their study reported torsion events (55.3\%) in first trimester vs (34.2\%) and (10.5\%) in the second and third trimester, respectively. In our case series also 6 out of $10(60 \%)$ patients presented when in first trimester pregnancy. Bilateral torsion, either simultaneously or sequentially, is infrequent, with few cases reported in the literature. ${ }^{12}$ Our case series presents an unusual case with multiple torsion, first left followed by multiple right ovarian torsion in the same patient. Our case series confirms the fact the torsion is more of a clinical diagnosis than ultrasound diagnosis as in all of our cases Doppler was inconclusive except one case where blood flow was partially decreased. No postoperative complications were noted and in all the cases the ovaries were proven functional by ultrasonography except one where oophorectomy was performed. We conclude that torsion of hyperstimulated adnexa in patients who conceived after gonadotropin therapy, is a special entity that requires more attention to achieve early diagnosis. Also, we would like to emphasize on the importance of clinical suspicion and confirmation by surgical exploration to salvage the ovarian function.

\section{CONCLUSION}

Diagnosis of ovarian torsion is a difficult task which requires good clinical awareness. High index of clinical suspicion is the most important factor in diagnosing adnexal torsion. Ultrasound with Doppler helps in diagnosing adnexal mass with torsion but should not be the sole diagnostic factor. Laparoscopy is not only useful for diagnosis but also for treating torsion with less morbidity. Conservative surgery is preferred for patients in the reproductive age group. 


\section{REFERENCES}

1. Maxwell KN, Cholst IN, Rosenwaks Z. The incidence of both serious and minor complications in young women undergoing oocyte donation. Fertil Steril 2008 Dec;90(6):2165-2171.

2. Royal College of Obstetricians and Gynaecologists. Ovarian hyperstimulation syndrome, management (Green-top 5, Sep 2006).

3. Chew S, Ng SC. Laparoscopic treatment of a twisted hyperstimulated ovary after IVF. Singapore Med J 2001;42(5): 228-229.

4. Pan HS, Huang LW, Lee CY, Hwang JL, Chang JZ. Ovarian pregnancy torsion. Arch Gynecol Obstet 2004 Sep;270(2): 119-121.

5. Arena S, Canonico S, Luzi G, Epicoco G, Brusco GF, Affronti G. Ovarian torsion in in vitro fertilization-induced twin pregnancy: combination of Doppler ultrasound and laparoscopy in diagnosis and treatment can quickly solve the case. Fertil Steril 2009 Oct;92(4):1496(e9-13).

6. Rackow BW, Patrizio P. Successful pregnancy complicated by early and late adnexal torsion after in vitro fertilization. Fertil Steril 2007 Mar;87(3):697(e9-12).
7. Weitzman VN, DiLuigi AJ, Maier DB, Nulsen JC. Prevention of recurrent adnexal torsion. Fertil Steril 2008 Nov;90(5): 2018(e1-3).

8. Pinto AB, Ratts VS, Williams DB, Keller SL, Odem RR. Reduction of ovarian torsion 1 week after embryo transfer in a patient with bilateral hyperstimulated ovaries. Fertil Steril 2001 Aug;76(2):403-406.

9. Smorgick N, Pansky M, Feingold M, Herman A, Halperin R, Maymon R. The clinical characteristics and sonographic findings of maternal ovarian torsion in pregnancy. Fertil Steril 2008 Dec;92(6):1983-1987.

10. Djavadian D, Braendle W, Jaenicke F. Laparoscopic oophoropexy for the treatment of recurrent torsion of the adnexa in pregnancy: case report and review. Fertil Steril 2004 Oct;82(4):933-936.

11. Taskin O, Birincioglu M, Aydin A, Buhur A, Burak F, Yilmaz I, et al. The effects of twisted ischaemic adnexa managed by detorsion on ovarian viability and histology: an ischaemia reperfusion rodent model. Hum Reprod 1998 Oct;13(10):2823-2827.

12. Frank M, Neeman O, Halperin R, Schneider D, Herman A, Panky M. Simultaneous bilateral torsion and entanglement of the adnexa. JSLS 2006 Oct;10(4):520-521. 